\title{
STUDI KRITIS TERHADAP RESPON MAJELIS ULAMA INDONESIA (MUI) TENTANG PEMANFAATAN MEDIA SOSIAL DALAM BERMUAMALAH
}

\author{
Subehan Khalik
}

Fakultas Syariah dan Hukum Universitas Islam Negeri Alauddin Makassar

\begin{abstract}
Muamalah through online media is one way to socialize Muslims Indonesia. Social media mediates between people communicating. Muamalah by utilizing the online world provides enormous benefits in developing the potential of people, such as in education, trade and services sector. However, on the other hand gives a gloomy picture of the use of the online world in the trade and services sector. There are many cases of online media abuse for prostitution, pornography, and fraud, which requires the MUI to intervene in anticipation of this issue with religious language. The Indonesian Ulema Council has responded to the use of the online world for the needs of social media in fatwa no 24 of 2017. The contents of this fatwa contrast leads to the wise use of social media to escape from hoax, bulying, slander, gibah and namimah. In another aspect, the MUI forgo the use of the online world for the needs of commerce in e-commerce. Another important aspect is the MUI's response to the needs of people in interacting in the online world, it is necessary to prepare an online desk that MUI immediately respond to the problems of the developing ummah to make MUI fatwa more rooted in the middle of the ummah as well as avoid religious radicalism.
\end{abstract}

\section{Keywords:}

Muamalah, Online Media, MUI Fatwa

\begin{abstract}
Abstrak
Muamalah lewat media online merupakan salah cara bersosialisasi umat Islam Indonesia. Media sosial menjadi perantara antar manusia menjalin komunikasi. Muamalah dengan memanfaatkan dunia online memberi manfaat yang sangat besar dalam mengembangkan potensi umat, seperti dalam dunia pendidikan, perdagangan dan sektor jasa. Namun, disisi lain memberi gambaran yang suram terhadap pemanfaatan dunia online dalam sektor perdagangan dan jasa. Ada banyak kasus penyalahgunaan media online untuk kebutuhan pelacuran, pornografi, serta penipuan, sehingga mengharuskan Lembaga MUI turun tangan mengantisipasi masalah ini dengan bahasa agama. Majelis Ulama Indonesia telah memberikan respon
\end{abstract}


terhadap penggunaan dunia online untuk kebutuhan media sosial pada fatwa no 24 tahun 2017. Isi fatwa ini kontras mengarah kepada penggunaan media sosial secara bijak agar lepas dari hoax, bulying, fitnah, gibah dan namimah. Pada aspek lain, MUI melupakan penggunaan dunia online untuk kebutuhan perdagangan dalam ecommerce. Aspek lain yang tidak kalah pentingnya adalah respon MUI terhadap kebutuhan umat dalam berinteraksi di dunia online, perlu kiranya MUI menyiapkan desk online yang segera memberi respon atas persoalan umat yang berkembang agar fatwa MUI semakin mengakar di tengah umat serta terhindar dari radikalisme beragama.

\section{Kata Kunci:}

Muamalah, Media Online, Fatwa MUI

\section{A. LATAR BELAKANG MASALAH}

$\mathrm{E}$ ksistensi manusia sebagai pemakmur bumi tidak terlepas dari fungsi manusia secara vertical dan horizontal. Fungsi vertikal mengarahkan manusia memperhambakan diri mereka kepada Allah. Sementara fungsi horizontal, mengarahkan manusia untuk saling terhubung antara satu dengan lainnya. Peneguhan dari fungsi ini mengharuskan manusia melaksanakan hubungan kepada sesama. Bentuk-bentuk hubungan manusia kepada sesama digambarkan dalam format muamalah.

Hukum Islam telah mengatur format muamalah pada pembinaan hubungan sesama melalui pemenuhan segala macam kebutuhan, baik primer maupun sekunder. Aneka kebutuhan yang dipertukarkan melalui proses perdagangan dapat terealisasi dalam bentuk jual-beli ataupun barter. Bentuk lain dari bermuamalah adalah dengan melakukan mu'āsyarah (pergaulan sosial) dalam bentuk perikatakan semisal perkawinan, sewa-menyewa, utang-piutang dan berbagai macam bentuk muamalah lainnya. Muamalah inilah yang melahirkan berbagai macam media yang dapat dijadikan sebagai alat penopang suksesnya muamalah.

Penipuan melalui media online sangat mudah terjadi sebab kemudahan akses dan intensitas setiap person dalam menggunakan media ini untuk bermuamalah. Massifnya arus informasi telah menyebabkan dunia online menjadi wahana yang sangat populer bahkan seorang netizen telah merasa jauh dari pergaulan ketika mereka terputus dari dunia online, meskipun sesaat.

Sebuah laporan dari JawaPos.com mengabarkan bahwa pada tahun 2017, telah terjadi peningkatan signifikan terhadap kejahatan penipuan lewat media online di kota Solo. Laporan ini memberi angka 900 kejadian dalam kurun waktu 2017, bahkan menurut pihak dari Mapolresta Solo terdapat sekurang-kurangnya tiga laporan 
penipuan online dalam sehari. ${ }^{1}$

Berangkat dari contoh kasus di atas, perlu kiranya pihak-pihak terkait mengamankan jalur perdagangan online lewat penegakan hukum serta pelibatan tokoh agama dalam mengurangi intensitas penipuan online lewat gerakan moril keagamaan. Tulisan ini Secara kritis akan mengurai bagaimana respon Majelis Ulama Indonesia terhadap muamalah di dunia maya, dengan sub masalah :

1. Bagaimana manfaat dan mudarat bermumalah di dunia online

2. Bagaimana Kritik atas respon Majelis Ulama Indonesia terhadap kejahatan online

\section{B. BERMUAMALAH DI DUNIA ONLINE, ANTARA MANFAAT DAN MAFSADAT}

Muamalah adalah peraturan-peraturan mengenai tiap yang berhubungan dengan urusan dunia, seperti perdagangan dan semua mengenai kebendaan, perkawinan, thalak, sanksi-sanksi, peradilan dan yang berhubungan dengan manajemen perkantoran, baik umum ataupun khusus, yang telah ditetapkan dasardasarnya secara umum atau global dan terperinci untuk dijadikan petunjuk bagi manusia dalam bertukar manfaat di antara mereka. ${ }^{2}$ sedangkan dalam arti yang sempit adalah pengertian muamalah yaitu muamalah adalah semua transaksi atau perjanjian yang dilakukan oleh manusia dalam hal tukar menukar manfaat. ${ }^{3}$

Menggunakan media online untuk bertransaksi pada semua aspek penopang hajat hidup manusia telah menjadi trend. Fakta ini terlihat dengan menjamurnya pemanfaatan koneksi internet untuk menyelesaikan keterhubungan antar manusia yang menjadi dasar utama muamalah. Pemanfaatan internet sebagai sarana bermuamalah oleh umat Islam di Indonesia mulai berlansung pada tahun 1997 dengan menggunakan sarana e-mail sebagai alat koneksitas yang menghubungkan Pusat Tekhnologi Tepat Guna (PUSTENA) Masjid Salman ITB dengan beberapa pondok pesantren di Indonesia. ${ }^{4}$ Meski hanya menggunakan email sebagai media, namun langkah maju mahasiswa ITB saat itu telah memberi dampak yang cukup positif dalam penggunaan media online dalam interaksi mumalah kaum muslimin di Indonesia.

Sisi lain dalam pemanfaatan media online dalam menopang muamalah kaum muslimin di Indonesia dapat terlihat pada penggunaan software (meskipun masih offline ketika itu) untuk mengadakan penelusuran dan mengutip hadis berikut terjemahnya dari sebuah software buatan anak bangsa yang bernama "Hadis

\footnotetext{
${ }^{1}$ https://www.jawapos.com/read/2018/01/19/182377/hati-hati-penipuan-online-merajalelasehari-tigakorban-kena-tipu

${ }^{2}$ Ahmad Ibrahim Bek, al-Mu'āmalah al-Syar'iyah al-Māliyahb (Kairo: Dār al-Intișār t. th). h. 15

${ }^{3}$ Minhajuddin, Fiqh tentang Muamalah Masa Kini (Ujungpandang: Fakultas Syariah IAIN Alaudddin, 1989). h. 10

${ }^{4}$ Subehan Khalik, Hukum Islam dan Penggunaan Telematika di Indonesia dalam "al-Daulah" Jurnal Hukum Pidana dan Ketatanegaraan (Fak. Syari'ah UIN Alauddin; Makassar, 2012), h. 63
} 
Sembilan Imam". Software ini berbasis web, namun saat itu masih digunakan secara offline dan cukup memberi kemudahan kepada kaum muslimin untuk mengunggah hadis Nabi, riwayat hadis yang bersangkutan serta mengurai jalur periwayatannya. Dapat dikatakan bahwa kehadiran software ini telah membantu para akademisi muslim yang berkecimpung dalam bidang ilmu hadis dan penelitian hadis memperpendek waktu penelitian mereka sekitar tujuh puluh persen. ${ }^{5}$

Seiring berkembangnya infra struktur internet di Indonesia, pemanfaatan media online untuk bermuamalah oleh kaum muslimin juga mengalami peningkatan yang cukup signifikan. Koneksi internet di Indonesia saat ini telah memasuki era jaringan serat optic. Jaringan ini memungkinkan pengguna menikmati layanan internet dengan kecepatan di atas $10 \mathrm{Mbps}$. Koneksi ini memungkinkan pengguna untuk memanfaatkan video call lewat media online tanpa takut disconnect atau mengalami perlambatan dalam memutar video. Sementara itu, setiap gawai saat ini telah dapat mengakses jaringan $4 \mathrm{G}$ yang besaran kecepatannya juga bisa di atas 10Mbps. ${ }^{6}$ Semua fasilitas internet yang maju tadi dapat dinikmati dengn murah, bahkan untuk menikmati kecepatan di atas 20Mbps, PT. Telekomunikasi Indonesia (Telkom) hanya menentukan tarif sebesar kurang lebih 350-500 ribu sebulan dengan kouta tak terbatas. ${ }^{7}$

Bertumbuhnya infrastruktur internet di Indonesia telah membawa angin segar dalam pemanfaatan media online dalam mengembangkan aspek-aspek sosial umat Islam. Dunia pendidikan telah mengalami pertumbuhan yang amat cepat lewat penggunaan koneksitas online serta pemanfaat media online. Salah satu perguruan tinggi agama Islam terbesar di Indonesia Timur (UIN Alauddin Makassar) telah menggunakan koneksi internet dan media online untuk kebutuhan akademik dalam portal akademik. Portal akademik UIN Alauddin Makassar telah menetapkan system realtime dalam setiap penginputan dan pengabaran hasil studi mahasiswa. Tidak hanya itu, system ini juga telah diterapkan pada pelaporan kinerja dosen yang akan dibayar lewat skema remunerasi. Penggunaan media online dan system internet secara apik membawa perubahan besar pada prestasi perguruan tinggi menjadi

\footnotetext{
${ }^{5}$ Saat ini software tersebut dapat diunggah dan dikoneksi secara online dengan menggunakan gawai atau laptop. Pembuat software ini menamai diri LIDWA PUSAKA. Penulis pada tahun 2010 telah memiliki software dalam versi offline, namun tidak dapat lagi memanfaatkan software ini jika melampaui penanggalan 2012, jadi solusi untuk menggunakannya adalah dengan mengundur tangga pada PC anda menjadi tanggal di bawah tahun tersebut. Untuk mengunjungi portal penyedia jasa layanan software ini anda dapat mengunjungi http://www.lidwa.com/produk-layanan/ensiklopedi-hadits-kitab-9-imam-versi-online/.

${ }^{6}$ Besarnya kecepatan internet ini membawa dampak revolusioner dalam penggunaan media online untuk bermuamalah. Bahkan Baznas telah memanfaatkan system cetak setoran zakat dengan system online, sehingga bukti setoran zakat dapat dijadikan sebagai pengurang pajak. Seorang muslim yang berdomisili di Indoensia dengan mudah dapat menghitung besaran zakat mereka cukup dengan mengunjungi portal https://globalzakat.id/.

7 Jika anda berminat menggunakan fasilitas super ini dengan biayan minim cukup mengklik https://wifi.id/findus, maka di hadapan anda akan tertera secara jelas peta dan area mana saja yang terdekat dari anda untuk menikmati jaringan tadi. Anda juga dapat menikmatinya di rumahan dengan cara kontrak kerjasama untuk waktu tertentu.
} 
PTKIN dengan peminat terbesar seluruh Indonesia pada tahun 2016. ${ }^{8}$ Perguruan tinggi ini telah mampu menerapkan sistem realtime dalam urusan akademik dan pemanfaatan sumber daya, sehingga mengukur kinerja para dosen dan mahasiswa dapat dengan mudah diketahui.

Keterhubungan umat Islam di Indonesia lewat media social juga telah mengalami revolusi besar-besaran. Jarak dan waktu telah berhasil mereka atasi dengan software berpola media social. Software-software ini mempertemukan setiap person dengan teman sejawat, saudara dan handai taulan mereka yang terpisah oleh jarak. Facebook, WhatsApp, Instagram dan beberapa software-software yang mengalih fungsi telepon dan surat menjadi ajang silaturrahmi dunia maya. Sebab ini pula memicu terjadinya pergeseran pada pola bisnis yang serba manual, menjadi bisnis berpola medsos berbasis system informasi. Inilah yang menyebabkan Indonesia telah bertumbuh menjadi Negara terbesar dalam pertumbuhan perdagangan lewat media online (e-commerce) pada tahun $2017 .{ }^{9}$

Angka pertumbuhan sebesar $40 \%$ diprediksi masih akan tumbuh mengingat jumlah penduduk Indonesia yang memiliki bank account baru 45\% sementara pada sisi lain, pemilik hp (gawai) sudah berada pada kisaran $85 \%$ penduduk. Artinya ada peluang bisnis online (e-commarce) memiliki peluang untuk tumbuh sampai dengan $40 \%$ jika proses transaksi tersebut menggunakan kartu debit atau kredit. ${ }^{10}$ Data ini menjadi penyemangat bagi pengusaha e-commerce untuk tetap mengepakkan sayap usaha mereka dan menciptakan system e-commerce yang semakin mumpuni dan terpercaya.

Bisnis online pada jasa angkutan juga telah jauh melakukan penetrasi pasar dan bahkan secara perlahan telah banyak membunuh perusahaan-perusahaan taxi. Grab. Uber dan Gojek telah merambah pasar transportasi Indonesia dan menawarkan system bertransportasi yang lebih murah dibanding taxi konvensional. Gojek pada sisi lain menawarkan jasa pesan-antar makanan (Go-food), layanan kurir instan (Go Seng) dan layanan berbayar dengan saldo (Go Pay). Jika diamati secara lengkap maka revolusi usaha dalam bisnis online (e-commerce) telah jauh bertumbuh mengalahkan kemampuan para pengambil keputusan dan pemakai jasa dalam mengukur dampak social dari perilaku dan pola bermuamalah di dunia online.

Revolusi bisnis online telah membawa manfaat yang besar terhadap pemenuhan segala macam kebutuhan mendasar rakyat Indonesia, namun di sisi lain dampak negative pada bisnis ini juga sangat kontras. Berbagai macam bantuk dan format kejahatan dunia maya juga membuncah sehingga menimbulkan kekhawatiran yang sangat mendalam. Dunia online seolah tumbuh menjadi momok dan menjadi daerah tak bertuan, sehingga pelaku bisnis di dalamnya dapat

\footnotetext{
${ }^{8}$ Lihat lebih lanjut http://edukasi.rakyatku.com/read/9224/2016/06/15/uin-alauddin-urutan-pertamapeminat-um-ptkin-2016

${ }^{9}$ https://www.liputan6.com/tekno/read/2957050/pertumbuhan-e-commerce-indonesia-ter tinggi -di-dunia

${ }^{10} \mathrm{https}$ ://buattokoonline.id/data-statistik-mengenai-pertumbuhan-pangsa-pasar-e-com merce-di-indonesiasaat-ini/
} 
berinovasi tanpa takut melanggar rambu-rambu yang ada.

Item paling utama dari dampak bisnis online adalah pemanfaatannya untuk kebutuhan bisnis haram semisal prostitusi. Konteks bisnis ini tidak lagi menjadi bagian bsinis orang-orang tertentu dengan tingkat kecakapan khusus, melainkan telah dapat dikerjakan dan digunakan oleh orang-orang biasa. Bahkan ibu-ibu rumahtangga pun dapat menjadi muncikari dalam bisnis haram ini. Berbekal sebilah gawai (hp), ibu rumahtangga telah dapat melaksanakan perannya selaku muncikari dari anak-anak peliharaannya. Facebook secara samar mereka gunakan untuk berkamuflase memasarkan perempuan-perempuan pemuas nafsu para lelaki hidung belang. Tidak tanggung-tanggung anak perempuan berstatus mahasiswa pun dijadikan sebagai wanita panggilannya. ${ }^{11}$

Sebagai gambaran awal, cobalah untuk mengadakan gogling di google dan tuliskanlah kata "bisnis prostitusi online" maka anda akan mendapati informasi yang sangat panjang bak tiada habis tentang bisnis ini. Meskipun informasinya adalah dugaan dan penangkapan pelaku bisnis, namun patut diperhatikan bahwa prostitusi juga telah melewati proses revolusi dan telah mengubah diri dalam bentuk lebih halus dan tak tersentuh. Dikatakan demikian sebab kamuflase online telah menyamarkan prostitusi menjadi menjadi bisnis komunitas sekaligus pelanggan dalam bentuk komunitas pula. Pada contoh di atas, komunitas pejabat di Aceh ternyata menjadi pelanggan dari bisnis prostitusi online ini.

Revolusi bisnis prostitusi dalam format prostituti gay dan lesbian juga mengalamai perubahan yang fantastis. Baru-baru ini tepatnya tanggal 21 Mei 2017 telah terjadi penagkapan besar-besaran di sebuah tempat fitnes berizin di Jakarta di sebuah ruko Kelapa Gading. Dalam penangkapan ini telah diamankan sebanyak 141 orang pria yang diinisialisasi sebagai pelaku pesta homoseksual. Mereka ditangkap setelah diintai kurang lebih dua pekan sebab petugas kepolisian sangat sulit mengakses tempat tersebut. Penangkapan ini adalah pengembangan dari informasi masyarakat yang curiga dengan tindak tanduk para lelaki yang keluar masuk dari ruko ini. Dari 141 lelaki yang tertangkap, empat orang dari mereka ternyata berkebangsaan asing. ${ }^{12}$ Pada peristiwa ini, pesta seks dalam prostitusi gay telah melibatkan orang asing yang mengetahui keberadaan tempat ini dari info online.

Kejahatan dunia maya (online) turut pula menjadi penyumbang utama kesemrawutan bisnis online di Indonesia. Jika perdagangan online (e-commerce) mengalami perkembangan yang sangat signifikan, maka penipuan berbasis online juga mengalami perkembangan yang signifikan pula. Korban penipuan online berjatuhan bahkan di beberapa daerah intensitas kejahatan ini bertumbuh sampai beratus persen. Sampel kota Solo yang telah dikemukakan pada prolog tulisan ini

\footnotetext{
${ }^{11}$ https://news.okezone.com/read/2018/03/26/340/1878089/dibanderol-rp2-juta-ayam-kam pus-di-acehpaling-disukai-kalangan-pejabat

${ }^{12} \mathrm{https}: / /$ megapolitan.kompas.com/read/2017/05/23/09405501/terbongkarnya.tempat. pesta.seks.kaum.gay.di.kelapa.gading
} 
menjadi contoh konkrit bertumbuhnya kejahatan serupa.

Pemerintah telah mengadakan beberapa upaya untuk mengadakan penertiban seputar bisnis online di Indonesia. Langkah paling kongkrit ke arah ini adalah penertiban penggunaan sim card yang terpakai pada gawai untuk memudah kan pengawasan terhadap pengguna gawai mereka. Penertiban dalam bentuk registrasi sim card berdasar nomor kartu keluarga atau KTP pemakai. Registrasi ini diharapkan dapat meredam penipuan secara online, baik dengan menggunakan sms maupun melalui telepon kurir. Meski masuk dalam modus tua, kejahatan melalui gawai telah menelan banyak korban bahkan sampai saat ini penipuan dengan imingiming hadiah, masih terus berlansung dan memakan korban. Upaya untuk meredam kejahatan penipuan diantisipasi dengan skema "Rekening Bersama". ${ }^{13}$

Skema ini menawarkn jasa perantara dalam bisnis online agar terjadi saling percaya antara penjual dan pembeli dalam bisnis online. Penjual dan pembeli terlebih dahulu sepakat menggunakan rekening perantara yang mereka sepakati yakni rekening bersama Indonesia. Rekening ini akan menerima transfer dari pembeli sementara pada sisi lain, penjual harus mengirimkan barangnya ke calon pembeli. Ketika barang diterima maka pembeli dapat menghubungi pemilik operator pemilik rekening antara untuk segera mentransfer dana mereka ke rekening penjual. Skema ini menjamin ketiadaan penipuan dibandingkan mentransfer lansung ke rekening penjual sebagaimana sering terjadi dalam bisnis online.

Pemilu dan Pemilikada merupakan ajang pesta demokrasi untuk mencari dan menjaring calon pemimpin ideal untuk bangsa Indonesia, juga tidak terlepas dari penggunaan internet secara negatif. Ujaran kebencian dan black-campaign telah menjadi menu harian di dunia maya, sehingga dapat dikatakan kalau dunia maya tak pernah sepi dari saling hujat dan saling mengurai borok masing-masing. Meski Komisi Pemilihan Umum dan Panwaslu telah mengatur regulasi berkampanye pada dunia maya, namun para pendukung dan simpatisan calon masih tetap menggunakan jalur negatif dalam dunia maya untuk menyerang kandidat. Fakta ini menguatkan dugaan jika internet dapat menjadi kontra produktif dengan demokratisasi, padahal internet adalah corong terkuat demokratisasi. Sebagai contoh peran Twitter dalam mendistribusikan berbagai rupa pendapat. Twitter telah mampu mendistribusikan percakapan pada masalah sosial dan politik setiap tahunnya lewat platform micro blogging. ${ }^{14}$

Keseluruhan fakta yang terurai di atas menguatkan dugaan bahwa telah terjadi revolusi dalam dunia digital dan berpengaruh lansung terhadap pola kehidupan masyarakat dalam berbangsa dan bernegara. Hal demikian juga terjadi pada sisi sosio kultural dan adat istiadat masyarakat pengguna telematika di Indonesia. Hampir semua aspek kehidupan telah mengalami perubahan seiring dengan semakin berkembangnya infrastruktur internet yang menjadi penopang utama dunia

\footnotetext{
${ }^{13}$ https://www.facebook.com/rekeningbersamaindonesia/posts/576110722457312

${ }^{14} \mathrm{http}: / /$ marketeers.com/peran-twitter-sebagai-corong-demokratisasi-digital-indonesia/
} 
online di Indonensia. Pemerintah selaku pemegang otoritas tertinggi dalam bernegara harus menjadi wasit yang adil dalam mengatur regulasi online agar tidak menjadi liar, demikian pula Majelis Ulama Indonesia selaku pemegang tampuk kebijakan beragama di Indonensia diharapkan mengambil posisi yang lebih kuat dalam memberi muatan moril dunia online agar tidak hampa nilai.

\section{KRITIK ATAS RESPON MAJELIS ULAMA INDONESIA TERHADAP MUAMALAH LEWAT MEDIA SOSIAL}

Majelis Ulama Indonesia telah mengeluarkan fatwa tentang Muamalah Lewat Media Sosial dalam fatwa no 42 tahun 2017 yang dirilis pada tanggal 13 Mei 2017 dan ditanda tangani oleh Prof. Dr. H. Hasanuddin AF, MA. Selaku ketua komisi Fatwa MUI dan DR. H. Asrarun Ni'am Sholeh, MA selaku sekretaris. ${ }^{15}$ Fatwa ini merupakan respon MUI atas berbagai perkembangan yang terjadi di dunia maya (online).

Fatwa MUI no 24 tahun 2017 berisi tentang pamanfaat dunia maya (online) untuk bermuamalah. Konten fatwa ini lebih condong pada aspek penggunaan dunia maya (online) untuk bersosial media. Sangat beralasan jika hal ini menjadi sorotan sebab penggunaan media sosial sangat membutuhkan regulasi yang pas untuk menghindari pengguanaannya ke arah negative. Fatwa MUI ini didasarkan pada hasil Munas MUI tentang infotaintmen tahun 2010 dan Halaqah bersama Kementrian Komunikasi dan Informasi RI pada tanggal 23 Januari 2017.16

Mengkritisi fatwa MUI tentang pemanfaatan media social dalam berinternet dalam kebutuhan muamalah, telah mengenyampingkan satu aspek yang cukup mendasar yaitu unsur e-commerce (pedagangan online) dalam amar fatwa. Mengamati data pengguna internet di Indonesia, data menunjukkan bahwa terdapat sekitar 82 juta pengguna internet cenderung mengunjungi situs online shop dan 71.6 juta cenderung mengunjungi situs media sosial. Data ini sekaligus memberi kesan bahwa keterwakilan pengguna media sosial dalam dunia maya memang mewakili mayoritas pengguna, namun pada sisi lain melupakan eksistensi pengguna yang cenderung kepada onlie shop yang menjadi mayoritas pengguna. Berikut dapat dianalisa pada visualisasi dalam diagram pengguna tersebut sebagai berikut $:{ }^{17}$

\footnotetext{
${ }^{15}$ https://mui.or.id/wp-content/uploads/2017/06/Fatwa-No.24-Tahun-2017-Tentang-Hukumdan-PedomanBermuamalah-Melalui-Media-Sosial.pdf

${ }^{16}$ Lihat kembali isi fatwa MUI No. 24 Tahun 2017 point tentang pertimbangan fatwa pada point 2 dan 3.

${ }^{17} \mathrm{http}: / /$ isparmo.web.id/2016/11/21/data-statistik-pengguna-internet-indo nesia-2016/
} 


\section{INFOGRAFIS HASIL SURVEY 2016}

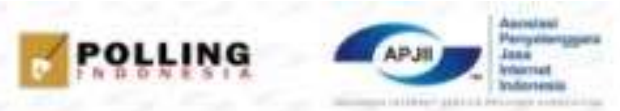

PERILAKU PENGGUNA INTERNET INDONESIA

(8) KONTEN KOMERSIAL YANGSERINGDI KUNUUNGI KONTEN MEDIA SOSIAL YANG SERING DI KUNUNGI

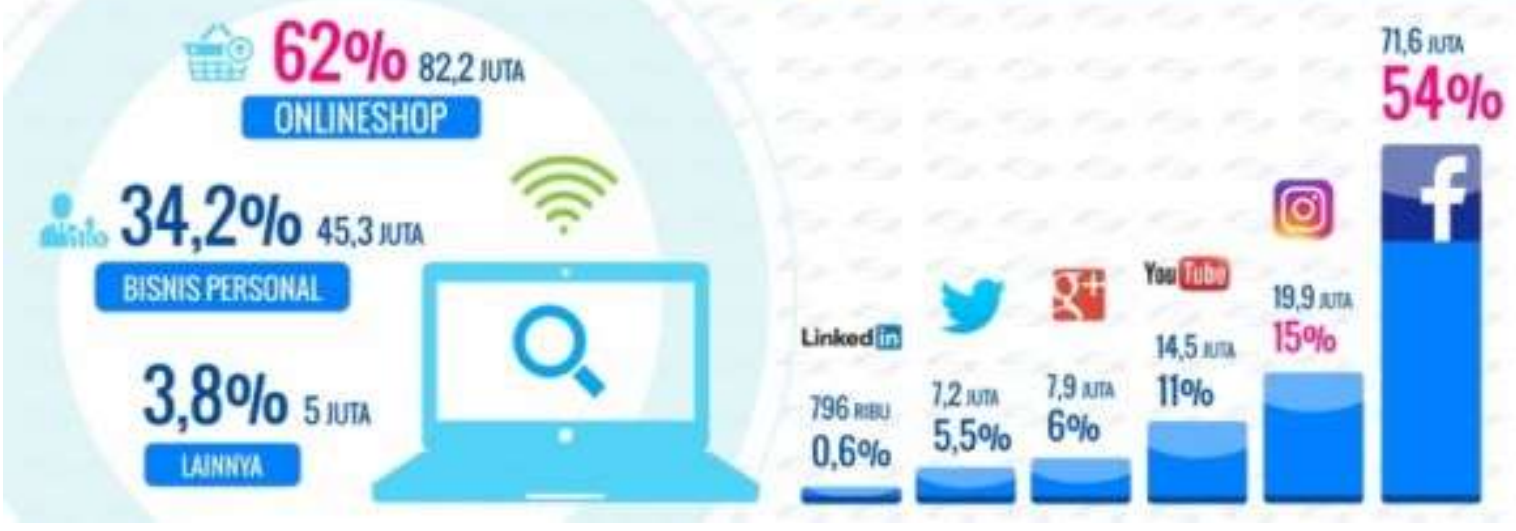

Rerata menunjukkan bahwa pengguna internet kebanyakan mengarah kepada online shop. Menandakan bahwa pada sektor ini, MUI tidaklah boleh alpa mengatur bagian ini. Penggunaan internet pada sektor online shop telah banyak menimbulkan korban penipuan yang merugikan pihak pengguna dalam jumlah materi yang cukup banyak.

Berasalasan jika dikatakan bahwa MUI perlu memberi respon yang cukup banyak terhadap pemanfaatan dunia maya dalam bermuamalah sebab sektor ini menjadi mayoritas kecenderungan pengguna. Media social dan e-commerce hendaknya mendapat perhatian yang serius mengingat pertumbuhan pendapatan perkapita nasional sangat terbantu dari sektor e-commerce. Banyak hal yang perlu mendapat kajian mendalam seputar pemanfaatan internet untuk bertransaksi dalam online shop sebagaimana diuraikan pada halaman 8 dengan rekening perantara. Apakah hal ini dapat dilegalkan dalam al-Ba'i ataukah perlu kejelasan lain yang menegaskan legalitas rekening perantara ini.

Respon dan tanggapan yang cepat MUI dalam pemberian fatwa terhadap perkembangan sosial dalam dunia online sangat dibutuhkan pada kondisi kekinian. Didasarkan pada kenyataan bahwa internet telah membawa perubahan revolusioner dalam format bertransaksi di dunia maya. Meski sangat ideal, namun saatnyalah MUI menyiapkan desk online yang akan menjawab segala permasalahan umat dengan segera. Misalnya pertimbangan hukum terhadap kehalalan pola penjualan, pembayaran dan pemasaran yang akan digunakan oleh pemasar e-commerce menjual barangnya. Pertimbangan ini dikemukakan bahwa pada saat ini umat cenderung meminta pertimbangan hukum dan fatwa di media online seperti youtobe.

Kecenderungan umat meminta fatwa dan pertimbangan hukum lewat tampilan 
youtobe pelan tapi pasti mengerus eksistensi MUI sebagai pemegang otoritas fatwa di Indonesia. Efek negative yang timbul dari kecenderungan ini melahirkan komunitas-komunitas eksklusif yang cenderung menggunakan bahasa agama untuk kebenaran yang mereka yakini. Lambat laun konten radikalisme agama tumbuh menjadi momok yang menakutkan dan menggambarkan Islam sebagai agama kekerasan. Badan Nasional Penanggulangan Teroris (BNPT) telah memberi empat penekanan pada situs internet yang dianggap punya potensi radikalisme sebagai berikut :

1. Ingin melakukan perubahan dengan cepat menggunakan kekerasan dengan mengatasnamakan agama.

2. Takfiri atau mengkafirkan orang lain.

3. Mendukung, menyebarkan, dan mengajak bergabung dengan ISIS/IS

4. Memaknai jihad secara terbatas. ${ }^{18}$

Konten radikalisme yang menjadi musuh bersama memerlukan kecermatan dan peran serta semua pihak untuk melawannya. MUI diharpkan menjadi garda terdepan pemberantasan faham ini agar umat dapat selamat dan menikmati kedamaian dalam Negara kesatuan republic Indonesia yang mereka cintai. Radikalisme dapat dilawan dengan bersatunya komponen bangsa dalam deteksi dini. MUI selaku pemegang otoritas keagamaan dapat menggunakan kekuatan mereka melawan radikalisme. Kemampuan MUI merubah diri lebih spontan dalam menjawab perkembangan dan permasalahan umat Islam di Indonesia akan menjadi perekat yang kuat melawan radikalisme beragama. versi-bnpt

${ }^{18} \mathrm{https}: / /$ www.cnnindonesia.com/teknologi/20150401093434-185-43429/kriteria-situs-islam-radikal- 


\section{KESIMPULAN}

Muamalah lewat media online merupakan cara bersosialisasi umat Islam Indonesia dalam meniti hubungan dengan sesama dan memanfaatkan media sosial sebagai perantara. Muamalah dengan memanfaatkan dunia online memberi manfaat yang sangat besar dalam mengembangkan potensi umat dalam dunia pendidikan, perdagangan dan sektor jasa. Sisi lain memberi gambaran yang suram terhadap pemanfaatan dunia online dalam sektor perdagangan dan jasa. Penyalahgunaan media online untuk kebutuhan pelacuran, pornografi, serta penipuan mengharuskan MUI turun tangan mengantisipasi masalah ini dengan bahasa agama.

Majelis Ulama Indonesia telah memberikan respon terhadap penggunaan dunia online untuk kebutuhan media sosial pada fatwa no 24 tahun 2017. Isi fatwa ini kontras mengarah kepada penggunaan media sosial secara bijak agar lepas dari hoax, bulying, fitnah, gibah dan namimah. Namun pada aspek lain melupakan penggunaan dunia online untuk kebutuhan perdagangan dalam e-commerce. Padahal berdasar survey pengguna tahun 2016, kecenderungan memanfaatkan dunia online untuk e-commerse lebih tinggi dibanding pengguna media sosial. Aspek lain yang tidak kalah pentingnya adalah respon MUI terhadap kebutuhan umat dalam bermuamalah di dunia online, perlu kiranya MUI menyiapkan desk online yang segera memberi respon atas persoalan umat yang berkembang agar fatwa MUI semakin mengakar di tengah umat agar terhindar dari radikalisme beragama.

\section{Daftar Pustaka}

Ibrahim Bek, Ahmad, al-Mu'āmalah al-Syar'iyah al-Māliyahb Kairo: Dār al-Intișār t. Th. Khalik,Subehan Hukum Islam dan Penggunaan Telematika di Indonesia dalam "alDaulah" Jurnal Hukum Pidana dan Ketatanegaraan Fak. Syari'ah UIN Alauddin; Makassar, 2012

Minhajuddin, Figh tentang Muamalah Masa Kini Ujungpandang: Fakultas Syariah IAIN Alaudddin, 1989

http://edukasi.rakyatku.com/read/9224/2016/06/15/uin-alauddin-urutan-pertamapeminat-um-ptkin-2016

http://isparmo.web.id/2016/11/21/data-statistik-pengguna-internet-indonesia-2016/ http://marketeers.com/peran-twitter-sebagai-corong-demokratisasi-digital-indonesia/ http://www.lidwa.com/produk-layanan/ensiklopedi-hadits-kitab-9-imam-versionline/.

https://buattokoonline.id/data-statistik-mengenai-pertumbuhan-pangsa-pasar-ecommerce-di-indonesia-saat-ini/ 
https://globalzakat.id/.

https://megapolitan.kompas.com/read/2017/05/23/09405501/terbongkarnya.tempat.pe sta.seks.kaum.gay.di.kelapa.gading

https://mui.or.id/wp-content/uploads/2017/06/Fatwa-No.24-Tahun-2017-Tentang-

Hukum-danPedoman-Bermuamalah-Melalui-Media-Sosial.pdf

https://news.okezone.com/read/2018/03/26/340/1878089/dibanderol-rp2-juta-ayamkampus-di-aceh-paling-disukai-kalangan-pejabat

https://wifi.id/findus,

https://www.cnnindonesia.com/teknologi/20150401093434-185-43429/kriteria-situsislam-radikal-versi-bnpt

https://www.facebook.com/rekeningbersamaindonesia/posts/576110722457312

https://www.jawapos.com/read/2018/01/19/182377/hati-hati-penipuan-onlinemerajalela-sehari-tiga-korban-kena-tipu

https://www.liputan6.com/tekno/read/2957050/pertumbuhan-e-commerce-indonesiatertinggi-di-dunia 